\title{
Trivium
}

Revue franco-allemande de sciences humaines et sociales - Deutsch-französische Zeitschrift für Geistesund Sozialwissenschaften

$12 \mid 2012$

La sociologie de la culture en Allemagne

\section{Les tâches de la sociologie de la culture}

Friedrich H. Tenbruck

Traducteur : Isabelle Kalinowski

\section{OpenEdition}

Journals

Édition électronique

URL : http://journals.openedition.org/trivium/4386

DOI : $10.4000 /$ trivium.4386

ISSN : 1963-1820

Éditeur

Les éditions de la Maison des sciences de l'Homme

Référence électronique

Friedrich H. Tenbruck, "Les tâches de la sociologie de la culture », Trivium [En ligne], 12 | 2012, mis en ligne le 20 décembre 2012, consulté le 08 septembre 2020. URL : http://journals.openedition.org/ trivium/4386; DOI : https://doi.org/10.4000/trivium.4386

Ce document a été généré automatiquement le 8 septembre 2020

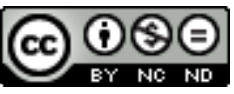

Les contenus des la revue Trivium sont mis à disposition selon les termes de la Licence Creative Commons Attribution - Pas d'Utilisation Commerciale - Pas de Modification 4.0 International. 


\title{
Les tâches de la sociologie de la culture
}

\author{
Friedrich H. Tenbruck
}

Traduction : Isabelle Kalinowski

\section{NOTE DE L'ÉDITEUR}

Nous remercions Madame Friederike Tenbruck, la revue Kölner Zeitschrift für Soziologie und Sozialpsychologie ainsi que la maison d'édition Springer VS de nous avoir accordé l'autorisation de traduire ce texte pour le présent numéro.

Wir danken Frau Friederike Tenbruck, der Kölner Zeitschrift für Soziologie und Sozialpsychologie sowie dem Verlag Springer VS für die freundliche Genehmigung, diesen Artikel in französischer Übersetzung zu publizieren.

1 Les tâches d'une sociologie de la culture ne peuvent être définies sans prendre en considération la situation générale de la discipline. La conception dominante veut que la société puisse être définie par son organisation extérieure, par les divisions qui sont partout manifestes dans la vie sociale et qui sont aujourd'hui désignées sommairement comme sa structure. Ce concept de société, nous aurons à le montrer, est davantage le produit de différentes circonstances contingentes qu'il ne se fonde sur une décision de principe ou sur des preuves empiriques. Quoi qu'il en soit, il en résulte, en pratique, que la société est identifiée avec sa structure et que la sociologie, par suite, est réduite à une analyse de cette dernière. Cette conception de la société ne laisse pas de place à la culture comme donnée autonome ; la sociologie de la culture, de ce fait, en est réduite à la portion congrue.

2 A l'encontre d'une telle conception, il faut rappeler que la réalité sociale englobe à la fois la structure et la culture et que celles-ci forment toujours une unité indissociable et ne peuvent être séparées l'une de l'autre que par l'analyse. Toute culture est inscrite dans des structures, toute structure est saturée de culture. La société appréhendée à travers ses seules structures et expliquée seulement à partir de ces dernières n'est pas 
suffisamment autonome, elle n'est pas déterminée et ne détermine pas tout le reste à partir d'elle-même, et, par suite, elle ne saurait constituer à proprement parler un objet de science. On ne peut décider a priori et une fois pour toutes quelle part revient à la culture et à la structure dans les phénomènes sociaux, car celle-ci varie; cette question doit être examinée sur un mode empirique, au cas par cas et en fonction de problèmes précis. Une sociologie qui, fondamentalement, se borne à étudier des faits structurels et cherche à déduire de ces derniers tous les autres phénomènes court ainsi le danger de se transformer en théorie coupée de la réalité. La crise de la sociologie, qui a fait couler beaucoup d'encre, est aussi l'expression d'une déception croissante face à un défaut de contenu réel dans les théories; on aspire désormais à sortir des pures analyses de structure.

Dans ce contexte, la tâche majeure d'une sociologie de la culture est de replacer au premier plan la réalité occultée par l'habitude que l'on a prise de se fixer sur les structures; il lui appartient de libérer la sociologie de sa conception réductrice et limitée de la société.

Tel est, de façon générale, le point de départ d'une sociologie de la culture. Celle-ci ne prend pas pour objet un domaine spécifique et séparé, qui coexisterait avec la société ; société et culture sont bien plutôt des distinctions nécessaires à l'intérieur d'une réalité dans laquelle toutes deux sont en permanence imbriquées l'une dans l'autre. Une sociologie de la culture ne peut donc isoler «le social» comme un domaine à part et autarcique ; elle doit justement montrer qu'une théorie de la société qui fait l'impasse sur les faits culturels est trop limitée. Etant donné la situation de la discipline, la sociologie de la culture ne peut constituer un nouveau domaine spécialisé; elle doit intégrer dans la sociologie générale les faits qu'elle prend pour objet et les perspectives qui sont les siennes. Par suite, elle ne peut pas être simplement une sociologie sectorielle de plus, qui transposerait les schémas courants de la sociologie dans un autre champ, en l'occurrence celui de la culture, sans que ces schémas de départ ne soient aucunement affectés par ces opérations. La sociologie peut manier à l'infini les faits culturels, il n'en ressortira pas une sociologie de la culture si celle-ci n'est pas déjà constituée. Ce qui doit être aujourd'hui au premier plan, ce ne sont pas les déterminations sociales de la culture - qu'il ne faut cependant jamais perdre de vue mais les déterminations et la signification culturelles des processus sociaux. La sociologie de la culture ne peut partir d'un primat de principe de la culture, mais elle ne peut s'arrêter à l'idée que « la société » constitue le réel proprement dit.

\section{Le lien d'ensemble entre les phénomènes culturels}

5 A défaut d'une tradition univoque et vivante, les études de sociologie de la culture sont confrontées au problème de trouver un lien entre les multiples tâches et thématiques qui leur incombent. Il suffit d'avoir une certaine conception de la «culture » pour pouvoir mentionner des problèmes méritant d'être traités d'un point de vue sociologique. Il serait impossible de les énumérer tous; le terme de «culture » est trop polysémique, la question est trop multiforme. Mais l'énumération de problèmes, si cruciaux soient-ils, ne crée pas le lien d'ensemble que présuppose le terme de " sociologie de la culture ».

6 C'est justement là que réside la première difficulté. Au vu de leur diversité manifeste, la question se pose de savoir quel lien unit les thématiques qui se rapportent à la culture, 
même si on se limite à la sphère qui concerne les sciences sociales. Il est difficile de définir le trait commun qui unifie au sein d'une même discipline l'étude de phénomènes aussi disparates que la culture primitive, les aires culturelles, la sousculture, la culture politique, la vie culturelle ou l'enculturation. Quelle perspective adopter en ce qui concerne les époques culturelles, l'homme cultivé, la culture quotidienne et la politique culturelle? Si l'on n'est pas en droit d'exclure ce type de thèmes d'une sociologie de la culture, on n'est pas davantage en droit, en l'état actuel de la discipline, de les réunir au sein de celle-ci.

7 La tâche la plus urgente d'une sociologie de la culture est donc de clarifier la base commune à partir de laquelle elle aborde les problèmes. C'est seulement dans ce sens que l'on parlera ici des tâches de la sociologie de la culture : non pour énumérer ou discuter des impératifs précis, mais pour définir avec précaution un point de repère qui lui confère une cohérence d'ensemble et aussi, au demeurant, une signification.

8 On a souvent déploré que, de ce point de vue, la langue n'offre pas une base satisfaisante, mais cela tient à la nature même du problème. En effet, c'est évidemment là une donnée de première importance pour la sociologie de la culture : les sociétés ne sont confrontées que tardivement à la contrainte de se comprendre, au moyen d'une notion objectivante, comme des «cultures». Nous reviendrons plus loin sur ce point. Quoi qu'il en soit, le concept de culture (ou l'un de ses équivalents immédiats) est un produit spécifiquement européen apparu depuis quelques siècles, qui possède, dans chaque pays, une multitude de significations, de surcroît très différentes d'un pays à un autre et sujettes, enfin, à des changements considérables.

9 A supposer qu'il soit possible de formuler de façon satisfaisante une définition scientifique, on ne serait pas plus avancé, car le lien d'ensemble entre les phénomènes si différents que nous classons comme culturels ne ressort pas de façon univoque de la simple description de la qualité générale en fonction de laquelle nous opérons ce classement. La question n'est pas de savoir quel est le trait commun à tous ces phénomènes, mais plutôt de se demander pourquoi la culture se manifeste dans une aussi grande variété de phénomènes. Elle ne doit pas être conçue comme une essence substantielle mais comme un phénomène vivant. Il est possible de retracer cette logique de déploiement de la culture, de l'esquisser à grands traits, et la sociologie de la culture a besoin, dans un premier temps, de cette topologie, afin de ne pas perdre de vue le lien d'ensemble entre les problèmes qu'elle soulève.

10 1. Dans leur multiplicité, les phénomènes culturels naissent d'une racine commune. Tous sont des manifestations de l'agir spécifique qui fait de l'homme un être de culture, ni entièrement régi par ses dispositions naturelles, ni simplement contraint par son intelligence à une adaptation optimale aux données extérieures. Sous sa forme générale, cette idée élaborée depuis Herder jusqu'à Cassirer, Plessner et Gehlen s'est imposée partout, même si elle a adopté certaines colorations nationales. Est considéré aujourd'hui comme culturel l'ensemble de l'agir, y compris les actions strictement soumises à une fin et simplement extérieures également inscrites dans le monde des significations symboliques où l'homme vit et agit ${ }^{1}$. Avec ce concept anthropologique de l'homme comme être de culture, on va au-delà des anciennes "dispositions", «facultés » et " pulsions », qu'il s'agisse de l'intelligence, de la volonté ou du désir, et l'on se réfère à l'agir, qui embrasse l'intérieur et l'extérieur, l'esprit et le corps au moyen de significations. Ce n'est que par le biais de telles significations, que l'homme doit créer pour lui-même, que se constituent pour lui le monde, le moi et la société. 
Cependant, il est rare que ces significations s'élèvent au rang d'une articulation explicite, notamment par le mime, le rite ou le culte, voire, en revêtant une forme verbale, soient détachées de l'agir et président à celui-ci. Bien que toute culture soit constituée par des significations symboliques, celles-ci demeurent bien souvent à l'état implicite dans l'action et ses objets. L'homme n'est par conséquent que partiellement en mesure de faire la clarté sur les significations qui portent son action, et peut encore moins acquérir la maîtrise de ces dernières. Dès lors que, pour lui, tout signifie, de nouvelles significations ne cessent de se forger dans l'agir. Pour toutes ces raisons, la culture ne saurait être une pure sphère de significations, séparée de l'action et de ses objets et imposée seulement à ces derniers.

11 Si le siècle précédent s'est égaré dans cette direction, l'on oublie aujourd'hui que, par le biais de significations qui, détachées de toute référence à un objet, sont cependant conditionnées pour devenir elles-mêmes des réalités pour les hommes, l'agir dépasse constamment le niveau des actes placés au service d'une finalité et celui des actes extérieurs. Ce point, la ligne de partage entre culture «matérielle » et « immatérielle », doit être marqué parce que les significations, ici, ne se réduisent pas à un simple moyen d'adaptation: l'homme dépasse la satisfaction de ses besoins. En tant qu'être de culture, il est aussi un être qui a la capacité, le vouloir et le besoin de culture. Il a de la culture parce qu'elle est pour lui un besoin. La constitution de son ordre de vie interne est pour lui un problème souvent moins pressant, mais non moins capital que l'établissement de ses conditions d'existence extérieures. L'ordre de l'action extérieure dépend de l'ordre de l'action intérieure, et celle-ci exige un ordre et une objectivation des significations. A cause de cette faculté contraignante de se créer une réalité propre à partir d'idées et de valeurs, l'homme a toujours été une énigme pour lui-même, et, quoique soumise à conditions, la formule classique qui dit que l'homme est aussi un être intellectuel et moral est indispensable, parce que juste. Dans toutes les sociétés, en effet, l'homme n'apparaît pas seulement comme le créateur et la créature des institutions et des règlementations sociales, mais aussi et tout autant comme celui de significations intellectuelles et morales à l'aide desquelles et à cause desquelles il a coutume de bouleverser et de transformer ces institutions et règlementations sociales, à tous les « stades » de développement social et culturel.

12 2. Ceci nous amène à aborder le deuxième concept de culture, le concept social. La culture ne peut en effet être appréhendée que dans la mesure où des hommes vivent ensemble. La société est le lieu où la capacité de culture de l'homme se réalise, où son besoin de culture est satisfait, faute de quoi une société ne pourrait exister. Dans la mesure où l'homme est un être de culture, les relations sociales doivent toujours aussi devenir culture, autrement dit développer des significations pour l'agir individuel et social, qui portent ce dernier. Leur spécificité, reconnaissable entre toutes dans l'économie, la société, les mœurs, la religion et le droit, qui revêt dans les idées et les valeurs porteuses d'une société le caractère d'une image du monde, fait partie des plus anciens savoirs que les peuples ont les uns des autres et d'eux-mêmes. Les sciences qui s'intéressent à la société ont cherché à rendre compte de différentes manières du caractère culturel de la société, mais elles se sont toujours accordées sur ce point : toute société dispose d'une culture propre qui est transmise à travers le temps ${ }^{2}$. La notion de culture renvoie ici aux modèles caractéristiques de la société dans son ensemble : c'est sa culture d'ensemble dans l'évidence d'une transmission sociale. L'approche sociologique de ces modèles ne peut bien entendu s'épuiser dans la restitution d'un contenu de pensée ; ils doivent bien plutôt être présentés « en action », autrement dit 
dans leurs manifestations cultuelles et rituelles, dans leurs ancrages sociaux, en abordant la problématique de leurs éléments multiples mais aussi contradictoires et en tenant compte de la distance infranchissable qui les sépare de la réalité. D'un autre côté, l'agir ne peut être compris dans son immédiateté sociale et sans recours aux modèles culturels qui le portent.

Il faut rappeler que, depuis Herder et ses aperçus décisifs, ce concept social de la culture, dans sa généralité, a particulièrement été élaboré par les sciences de l'esprit (Geisteswissenschaften) allemandes, avant d'être transmis aux sciences sociales, pour lesquelles société et culture ont longtemps été des concepts interchangeables. Par le truchement de l'anthropologie culturelle, cette notion a également été intégrée dans le concept de société de Talcott Parsons, mais seulement sous la forme générale que lui avait donnée la dite anthropologie culturelle. Ses formules se retrouvent aujourd'hui encore dans les publications sociologiques, lorsqu'il est question de "culture patterns " et de "cultural heritage ", d'un fonds de "valeurs et normes" générales ou d'un "consensus sur les valeurs». Cependant, ces notions passées par le filtre de l'anthropologie culturelle ne sont guère opérationnelles pour la sociologie, parce que l'approche anthropologique s'est développée à partir de l'étude de sociétés simples, et que, de ce fait, son outillage conceptuel et méthodologique n'est pas suffisant pour appréhender en tant que cultures d'autres types de sociétés, de façon suffisamment pertinente d'un point de vue sociologique. De fait, on est en droit d'affirmer qu'en général, toutes les sociétés présentent des modèles culturels spécifiques. Il est également vrai que, partout où elle tente de pénétrer les mondes de signification subjective de l'agir social, l'observation participante découvre des modèles culturels, comme l'attestent également les travaux phénoménologiques et interactionnistes. La sociologie de la culture ne peut renoncer à tous ces apports, mais elle ne peut s'en tenir là. L'anthropologie culturelle part de l'hypothèse que la culture est également répartie dans la société et partout implicitement impliquée dans l'agir ; en d'autres termes, que la culture dans son ensemble et la culture quotidienne ne font qu'un. Mais cela ne vaut que pour les sociétés simples. Si l'on applique ce concept à d'autres sociétés, il permet d'appréhender les cultures du quotidien, les sous-cultures et les cultures de groupes, mais non la culture d'ensemble de ces sociétés.

3. En effet, de même qu'on peut observer des sauts qualitatifs dans la différenciation sociale, il en va de même dans l'évolution culturelle, de façon en partie parallèle. Tout concept universaliste de la culture trouve sa limite dans la transformation des formes de la culture, qui peuvent s'agréger de multiples manières. Dans la culture supérieure, l'égalité de répartition fait place à une culture de représentation dans laquelle la possession de culture est socialement différenciée. La culture doit être désormais exposée de façon systématique dans des doctrines et des objectivations explicites, et doit par suite être confiée à un nouveau groupe, l'intelligentsia. Son influence est pour une part garantie par des institutions qui relèvent parfois de son autorité, mais peuvent également se rattacher à d'autres formes d'autorité. Dans d'autres cas, cette influence se fonde sur la compétence et la supériorité intellectuelles de ce groupe.

La culture peut ainsi être saisie, d'un côté, dans des doctrines explicites et des institutions spécifiques, ce qui incite à un découpage de la notion de culture en différents secteurs. La sociologie de la culture peut alors correspondre à une étude des domaines culturels autonomisés. Cependant, qu'on privilégie plutôt les doctrines et les contenus ou bien les institutions et leur fonctionnement, la sociologie culturelle est 
confrontée, dans les deux cas, à la question de savoir quel rôle jouent ces secteurs de production et de gestion de la culture pour la société dans son ensemble, et par quels modèles culturels la société dans son ensemble a été portée et effectivement marquée dans son agir. D'un autre côté, en effet, dans la mesure où son interprétation et la poursuite de son développement sont confiés à une intelligentsia particulière, la culture se fractionne. Une culture de représentation tend à se constituer dans des rapports variables entre intellectuels et couche dominante, et à recouvrir progressivement la culture populaire, sans parler ici d'autres différenciations. Il suffit d'évoquer ici les études de sociologie religieuse de Max Weber pour mesurer à quel point il est difficile de découvrir, dans le triangle que nous venons d'esquisser très schématiquement, les modèles porteurs qui caractérisent de telles sociétés en tant que cultures. Là encore, la culture doit toujours être considérée " en action », comme on l'a dit plus haut. Il s'agit d'évaluer les points d'ancrage sociaux de l'intelligentsia productrice ou porteuse de culture, la portée de ses idées et de ses normes dans l'agir, la multiplicité et le caractère indéfini des éléments culturels, au vu des circonstances qui infléchissent l'agir, et, enfin et surtout,de tenir compte des courants sociaux antagonistes ou de percées charismatiques. Cependant, il ne fait pas de doute que la culture, dans la mesure où elle est soustraite à la vie collective et confiée à un groupe séparé (une intelligentsia de la culture) et accède par là à des formes objectivées, peut trouver ainsi une force et une dynamique jusque là inconnues, qui se fondent pour une large part sur la puissance potentielle des idées. La simple tradition ne suffit plus. La culture devient elle-même une tâche à remplir et un problème. Le fait que les idées puissent devenir des forces motrices dépend de bien des facteurs. Pourtant, il serait absurde d'en nier a priori la possibilité, si l'on songe que les fondations des religions, mais aussi la science grecque, les Lumières ou le marxisme ont mis en mouvement des courants de l'histoire universelle. En pratique, cependant, la sociologie professe un tel non-sens lorsqu'elle entreprend de présenter l'histoire comme un simple mouvement social et prétend pouvoir expliquer les idées en désignant leur trame sociale. Il n'est pas de composante de la culture à l'égard de laquelle la résistance de la sociologie soit si vive qu'à l'égard de celle-ci. Cela tient à beaucoup de raisons, mais présente surtout un avantage : la sociologie évite ainsi d'avoir à rendre des comptes quant au pouvoir culturel qu'elle exerce elle-même en défendant l'idée que la société est la matrice de la réalité.

16 4. Lorsque la culture prend forme dans des institutions et des objectivations spécifiques, elle passe de l'état de simple tradition à un autre régime : elle devient alors une tâche à remplir et un problème, à la fois subjectif et objectif. Soustraite à la communauté de la vie sociale, la culture a besoin d'être transmise et diffusée par des dispositifs institutionnels spécifiques. Elle devient un problème éducatif objectif et subjectif. L'existence de patrimoines culturels contraint la société à les acquérir pour les posséder. En effet, dans la mesure où les objectivations culturelles ne se transforment pas en un savoir purement spécialisé et surtout purement technique, destiné à n'être transmis qu'à un petit nombre de spécialistes, dans la mesure, en d'autres termes, où les objectivations culturelles se transforment en un savoir nécessaire pour une strate importante de la vie publique, un savoir général et, justement, représentatif, il doit être transmis par le biais d'institutions éducatives. La forme de transmission de ce savoir (un apprentissage scolaire au sens le plus large du terme) entre ainsi en conflit avec le rôle qui est le sien, celui d'une sphère détachée de l'agir et qui s'est imposée aux dépens de modèles d'action traditionnels et vécus, mais 
qui a cependant su se rendre indispensable. La société qui a pris forme dans des objectivations culturelles ne peut se perpétuer qu'au prix d'une appropriation personnelle et d'un effort d'intériorisation intellectuelle qui transforme le savoir en espace d'action personnel. Telle est la genèse de la définition de la culture comme tâche subjective, et, par là même, comme processus, que Simmel a décrite dans son article sur la tragédie de la culture ${ }^{3}$.

Il serait dès lors facile de déduire de cette topologie générale quantité de tâches à remplir pour la sociologie de la culture. Mais cette esquisse avait seulement pour but de montrer le lien qui unit les concepts et les phénomènes culturels dans leur multiplicité. A chaque fois, il en va de la capacité et de l'obligation, inscrite dans la spécificité humaine, de garantir l'existence d'un monde de significations pour l'agir qui dépassent la simple calculabilité de la réalité extérieure et intérieure. Pour la sociologie de la culture, qui traite des modèles communs de signification de l'agir social, ce problème se subdivise de multiples manières au fur et à mesure que la société et la culture changent de forme. La culture peut se présenter sous une forme tantôt implicite, tantôt explicite, elle peut être également partagée ou stratifiée, elle peut s'affirmer comme la culture d'une société dans son ensemble ou comme la culture d'un groupe, selon les degrés variables d'institutionnalisation et de différenciation; parfois la culture est une tradition établie, parfois elle devient un problème et une tâche à remplir. La sociologie de la culture doit être consciente que la forme de son objet est ainsi sujette à variations; elle n'est pas en droit de canoniser un problème unique, une perspective unique, un domaine unique; elle ne peut développer une théorie et une méthode impératives à partir d'un seul phénomène. Quel que soit le thème choisi comme objet d'étude, il importe de garder en tête cette topologie des problèmes.

\section{Histoire du problème}

Nous sommes si habitués au concept structurel de société que nous ne percevons plus guère son caractère réducteur. Rappelons donc tout d'abord que la sociologie ne s'est en aucun cas développée en étudiant les seuls faits structurels. D'emblée, des faits culturels ont également joué un rôle, lorsqu'ils semblaient eux aussi renvoyer au jeu de puissances supra-individuelles. Pour une part, la science sociale a justement été pratiquée comme une science de la culture -et pas seulement dans le cas, bien connu, de l'ethnologie (Völkerkunde)-; le terme de "société " a conservé, jusqu'au $\mathrm{XX}^{\mathrm{e}}$ siècle encore, une signification large, désignant tout simplement l'ensemble des phénomènes observables dans un pays -autrement dit, en un sens, tout ce que font les hommes pour autant qu'ils forment une société. En ce sens large, la société incluait la culture, et ces deux notions étaient même tenues pour interchangeables. D'un autre côté, on pouvait parler de la société au sens restreint, c'est-à-dire de ses groupes, institutions et réglementations. Même dans cet usage structurel du terme, les faits culturels continuaient à jouer un rôle comme données spécifiques, y compris lorsqu'ils n'étaient pas expressément désignés comme tels ${ }^{4}$. Ce n'est qu'au cours du XIX ${ }^{e}$ siècle que le concept de société a été restreint à certains phénomènes dès lors tenus, de façon privilégiée, pour la composante proprement sociale de la société, et qui sont ainsi devenus l'objet d'une science spécifique. Cet objet plus restreint, limité, pour l'essentiel, à la configuration et à l'organisation sociale, et donc aux relations, groupes et institutions sociaux, avec leurs classifications extérieures et intérieures, leurs 
hiérarchies et leurs subdivisions, a ensuite été élaboré par le biais d'une analytique générale, dans un processus d'abstraction plus poussé. La notion sociologique de société est donc une construction qui est le produit d'une double abstraction, même si elle est traitée par les sociologues comme une réalité immédiate. Au demeurant, ce caractère d'abstraction n'a rien de répréhensible. Toutes les sciences et même notre pensée quotidienne se fondent sur l'abstraction (autrement dit sur l'omission de certains objets et de certaines caractéristiques) qui seule nous permet d'isoler un élément important dans la réalité. Abstraire de la réalité un domaine d'objet n'a cependant de sens que dans la mesure où celui-ci est relativement ordonné, cohérent et autonome. Nul ne saurait affirmer que les structures sociales sont entièrement dépourvues de lien d'ensemble, et nul ne saurait nier que la sociologie a le mérite d'étudier ces liens d'ensemble. Mais l'ampleur et la portée de ces derniers dépendent de données empiriques. Cependant, la sociologie présuppose que les structures forment un domaine spécifique et autonome. Sans se demander sérieusement si l'on ne pourrait pas apporter la preuve du contraire, on s'en tient au fait banal que tout est socialement conditionné, comme si tout n'était pas également culturellement conditionné. Au lieu de voir dans l'analytique des théories de la structure une clé privilégiée pour l'étude des différentes conditions et données sociales, on en a fait la substance de la sociologie. Par suite, le gain initial s'est de plus en plus transformé en perte, l'enrichissement en appauvrissement, l'extension en limitation. En effet, avec la radicalisation conséquente du double processus d'abstraction, la construction élaborée par le travail sociologique la « société »- a eu tendance à devenir une réalité en soi et l'unique réalité. Ce qui avait été, au départ, la découverte d'une nouvelle trame de la réalité est devenu l'absolutisation d'une composante. Le «social » est devenu le noyau de la réalité, la construction s'est muée en réalité, d'autres domaines de réalité ont été occultés et réduits à des épiphénomènes, et il n'est plus resté que « la société » et les controverses relatives à sa définition. La sociologie s'est enfermée et nous a enfermés dans le cadre clos du monde comme société.

Pour mesurer l'ampleur de cet enfermement, il faut observer l'évolution de la sociologie en lien avec l'ensemble de cette branche du savoir. Si, dans la configuration des sciences, la sociologie était demeurée une discipline spécialisée, dans laquelle quelques connaisseurs avaient entrepris d'étudier le social à l'état pur, la limite de leurs abstractions partiales serait restée visible -sinon de façon consciente et théorisée, $\mathrm{du}$ moins de façon inconsciente et en pratique. Aussi longtemps que les autres sciences de l'homme, ce qu'on appelle les "sciences de l'esprit», étaient florissantes, aussi longtemps qu'elles faisaient partie du tronc commun de la culture officielle, que les sociologues devaient passer par l'étude de ces dernières avant d'accéder à leur discipline et qu'ils puisaient leurs données dans le corpus de savoirs de ces mêmes sciences, «le social » n'avait guère de chances de revêtir les contours d'une réalité autonome, comme nos classiques nous l'enseignent en permanence. Mais à partir du moment où les sciences de l'esprit ont commencé à perdre elles-mêmes leurs certitudes, les sociologues à être recrutés au terme des seuls cursus de sociologie et la sociologie à se doter, avec les enquêtes sociales, d'instruments spécifiques de collecte des données, coupant ainsi le cordon qui la rattachait au corpus de savoirs des sciences de l'esprit et employant ces outils pour extraire pour ainsi dire de la réalité le "sociétal » à l'état pur, l'abstraction de la sociologie a commencé à se falsifier ellemême en se faisant passer pour la réalité. Ce qui avait pu enrichir notre connaissance 
de la réalité humaine s'est présenté dès lors comme le seul savoir essentiel sur la réalité " authentique».

Ce constat est particulièrement frappant dans les cas où la sociologie a tenté de sortir de la cage de verre du « social » et de reconquérir après coup, au moyen de sociologies sectorielles, les larges domaines qu'elle avait auparavant exclus. A quelques exceptions et résultats ponctuels près, il n'en est guère ressorti au final autre chose qu'une production de métastases: les schémas sociologiques, transposés dans tous les domaines extra-sociaux, y ont proliféré jusqu'à devenir des réalités autonomes et à anéantir la réalité extra-sociale initiale. En effet, toutes ces sociologies sectorielles qui ont surgi en grand nombre et peuvent se multiplier à l'infini suivent le même schéma. Elles ont toutes au départ le vague projet d'étudier les relations entre la société et, disons, la littérature ; les présupposés sociaux, les conditions et les formes sociales sous lesquelles celle-ci se manifeste sont alors analysés dans les moindres détails, à tel point qu'il ne reste plus rien de la littérature, en l'occurrence, selon sa logique propre et sa signification singulière. La religion disparaît derrière son organisation et sa fonction, la littérature derrière ses conditions sociales et ses finalités sociales, la science derrière ses structures extérieures. Tous les corpus de savoirs qui avaient été considérés comme réels, du moins dans des époques antérieures, sont engloutis dans cette sociologisation qu'il faut bien appeler totale, et, à la fin, il ne reste plus que «le social». Le reste n'a plus d'importance, ce n'est plus qu'un épiphénomène, une idéologie, un reflet, une superstructure. Tout est explicable par le social et tient sa réalité de ce dernier. Toute incursion dans un domaine nouveau ne peut aboutir qu'à la confirmation des schémas sociologiques bien connus.

Il ne faut pas oublier, cependant, que toute interprétation de la société est inévitablement une interprétation de l'homme. Si l'on mesure la réalité à l'aune des résultats de la sociologie actuelle, on a affaire à un homme qui n'agit qu'en fonction de motivations et de déterminations sociales; car les structures ne peuvent constituer un objet autarcique que dans la mesure où l'homme est ainsi engoncé dans ces dernières, qu'il a intérêt à leur existence et qu'il est déterminé par elles. Il manque ce qui aurait malgré tout donné à l'œuvre de Weber la marque de la sociologie de la culture, même s'il n'avait pas traité de problématiques attachées à celle-ci: le sens de la multidimensionnalité des motivations et des compréhensions humaines, que la sociologie actuelle exige de recadrer aux dimensions du «social» et de lui seul. Max Weber n'a jamais perdu de vue que le sens de l'agir se ramifie à l'infini et dépasse nécessairement «le social». Le rétrécissement qui s'est imposé dans la sociologie n'est pas le résultat d'un parti pris fondé ; il est la conséquence indirecte d'une perspective de recherche, et n'a donc jamais besoin d'être explicité ni justifié.

De la même façon, la sociologie n'a jamais été jusqu'à renier fondamentalement et explicitement l'importance sociale de la culture. Ce n'est que dans l'orbite du marxisme qu'on en est arrivé là, en fixant radicalement la société au stade des infrastructures et des moyens de production, et en déclarant que le reste n'est que simple superstructure. Bien que cette vision n'ait pas tardé à déclencher de multiples controverses au sujets des facteurs réels et idéels (autrement dit, pour employer les termes de Max Weber, des intérêts et des idées), la sociologie n'a pas suivi Marx. Elle a plutôt oublié la culture, sans que cet oubli fût explicitement motivé. Ou plutôt: elle a développé à froid sa propre théorie de la superstructure et de l'infrastructure, dans laquelle le facteur décisif n'étaient plus les intérêts et les déterminations purement économiques, mais 
ceux qui étaient inscrits dans les structures; dès lors, «la société » est devenue la réalité proprement dite, tandis que la culture n'était plus qu'une façade et une superstructure. En ce sens, la sociologie actuelle, dans ses grandes tendances, est un marxisme généralisé, qui pratique sa théorie de la superstructure et de l'infrastructure sans la professer explicitement. Le refoulement de la culture hors de la sphère de la sociologie s'est fait sans bruit. Une œuvre d'une influence aussi considérable que celle de Parsons confirme l'hypothèse selon laquelle la conception réductrice que la sociologie actuelle se fait de la société n'a pas été le produit d'une prise de position claire et responsable au sujet du pouvoir social de la culture.

C'est là l'un des paradoxes de l'histoire des sciences: la théorie des structures de Parsons a été marquée de façon décisive par l'anthropologie culturelle américaine, qui, à partir des traditions des sciences de l'esprit allemandes, avait forgé l'idée générale que, dans la vie collective de hommes, la culture était donnée comme une unité de signification fonctionnelle, pour l'essentiel dépourvue de finalité, mais transmise avec art par la socialisation, qui garantissait l'unité de la compréhension et de l'agir. De cette conviction qui, à l'époque, avec la caution de la psychanalyse, tournait principalement autour du thème culture and personnality, Parsons a tiré pour sa part la conception bien établie selon laquelle toute société dispose d'un tronc commun de valeurs et de normes générales qui coiffent les particularités des rôles, des groupes et des institutions et remplissent une fonction d'intégration. Pour Parsons, la culture était un donné préétabli et incontestable, produit par la société et susceptible, en cas de troubles, d'être adéquatement reconstituée par celle-ci. Elle n'appelait donc pas un traitement sociologique spécifique. Par suite, il n'est nullement contradictoire que Parsons ait enjoint ses élèves de ne pas ignorer la culture comme donnée spécifique, à côté des systèmes de l'homme et de la société, mais n'ait eu personnellement rien à dire à son sujet $^{5}$. Parsons n'a pas vu qu'il n'est pas légitime de prendre pour donnée de départ la culture dans les sociétés primitives, strictement conditionnée et non problématique, pour en conclure que la culture, de façon générale, ne pose pas problème. La théorie structurelle s'est développée avec la conviction confiante que toute société produit une culture d'intégration. Et l'accord fonctionnel des parties de la structure était, au fond, la transposition à la structure du concept d'unité fonctionnelle que l'anthropologie culturelle avait développé pour le cosmos de significations de la culture. Les normes et valeurs d'intégration présupposées comme allant de soi ne pouvaient exister que parce que la structure était cohérente d'un point de vue fonctionnel. Le concept de culture développé à partir des sociétés primitives avait été transposé, par des voies singulières, à toutes les sociétés, mais ce présupposé demeurait cependant fondamentalement opaque. Dans ce contexte, il était impossible d'élaborer une approche des processus spécifiquement culturels, en particulier de la problématique de ces derniers dans les cultures développées et dans les sociétés modernes sécularisées ${ }^{6}$.

De cette manière, ce qui était au départ un gain d'abstraction est devenu le carcan étouffant d'une image du monde qui passe de plus en plus à côté de la réalité. Ce constat est particulièrement patent lorsque la sociologie s'intéresse à des évolutions sociales d'un point de vue historique ou prospectif, en d'autres termes lorsqu'elle aborde le passé ou l'avenir. Quelle contribution peut apporter à l'explication des processus historiques une discipline qui, au moyen d'une connaissance descriptive, à savoir la structuration et la différenciation sociales, transforme les structures sociales en processus autonome et indépendant, voire en simple automatisme historique dont les grands événements culturels (disons la science et la philosophie grecques, les 
fondateurs de religions et les réformateurs, tels le Bouddha, le Christ, Mahomet, Luther, mais aussi les Lumières, le marxisme et le nationalisme) se trouvent exclus comme accessoires et sans importance, tandis que les évolutions ainsi déclenchées, qui ont pour certaines été déterminantes pendant des millénaires, et marquent encore à bien des égards notre réalité d'aujourd'hui, sont désignées comme les épiphénomènes de situations sociales? La croyance dans l'auto-détermination de la société, censée se perpétuer par génération spontanée, fait que la sociologie a recours à l'histoire parce qu'elle ne comprend pas les moments de rupture où des réalités tout à fait inédites s'imposent dans la société, en la transformant et en la bouleversant. Rien d'étonnant, par conséquent, si, comme on l'a vu tout récemment avec la révolution culturelle, ses visions d'avenir passent si souvent à côté de la réalité, faute d'avoir su intégrer les couches de réalité qui ne sont pas sociales au sens étroit du terme. Dans toutes ces évolutions, précisément, des faits culturels et d'autres types de faits se mêlent aux faits sociaux.

Au fur et à mesure de son évolution, les approches, les composantes et les conceptions culturelles de la sociologie ont ainsi été réduites à la portion congrue. La sociologie actuelle a jeté l'anathème sur le plaidoyer de Dilthey pour une prise en compte des systèmes culturels. De Simmel, éminent doctor utriusque de la réalité, on n'a gardé que les approches sociologiques formelles, qui, chez lui, ne s'animaient que par la maitrise et la prise en compte de réalités historico-culturelles. On a réservé le même traitement à Max Scheler, sans parler des tentatives d'Alfred Weber pour élaborer une sociologie de la culture. En Max Weber, la plupart des sociologues ne voient plus que le prophète de la théorie structurale, dont l'œuvre est censée livrer des hypothèses à vérifier. De l' impetus que l'anthropologie culturelle a insufflé à la sociologie américaine, il n'est resté que des platitudes, affadies et banalisées, telles que l'« héritage culturel partagé », les « traits et modèles de culture » et un concept de « socialisation » mal compris ${ }^{7}$. Partout, le domaine de la culture est présenté comme divisé en rôles spécifiques, ou bien comme une vague sphère de valeurs générales. La culture devient un fait social qui ne sert plus qu'à entretenir le fonctionnement de la société. Dans bien des introductions à la sociologie, la référence à la «culture " comme clause de sauvegarde, qui permet de l'oublier plus complètement ensuite, procède aussi de cette forme castrée. Les approches intéressantes sont le plus souvent étouffées dans des raisonnements sociologiques soporifiques, comme dans Enter Plato d'Alvin Gouldner, et les bons travaux sociologiques sur la culture sont le plus souvent le fait d'auteurs qui ne savent rien de la sociologie, comme Auerbach ou Snell, comme de certains spécialistes de littérature, théologiens, historiens, et tout au plus des marginaux de la sociologie.

Ce ne sont pas là des hasards et des pannes momentanées, c'est le cours de la sociologie, qui suit la direction dans laquelle souffle le vent de l'époque. Dans cette situation, force est de s'interroger sur les circonstances qui ont entraîné ce rétrécissement de la société à sa structure, devenu entre temps un truisme, et élevé ainsi cette structure au rang de réalité sociale véritable.

\section{Les raisons de l'occultation de la culture}

La réduction de la société à sa structure est le produit de différentes inhibitions et difficultés qui ont réduit à néant les multiples tentatives d'élaboration d'une sociologie de la culture. Le concept méthodologique qui a promu une science strictement 
empirique et systématique a joué un rôle important, tel qu'il s'est imposé, notamment, dans la conception américaine d'une "social science ». Le caractère empirique de la discipline pouvait plus facilement être appréhendé à partir des faits structurels, qui semblaient pouvoir être saisis de façon objective, qu'à partir des faits culturels, au caractère impalpable, qui semblaient ne jamais se prêter à une définition univoque, ni pouvoir constituer des variables susceptibles d'être isolées dans le cadre systématique de la science nomothétique (Gesetzeswissenschaft) que l'on aspirait à construire ${ }^{8}$. Par leur caractère manifestement individuel, les faits culturels ont en outre opposé une résistance à l'idée d'évolution et à la comparaison. Historiquement, ils se présentent au sein d'une multiplicité d'ordres impossibles à comparer, alors que les structures sociales, elles, semblent s'ordonner dans la continuité d'une série d'évolution. La culture est fermée au concept de science nomothétique, et les quelques tentatives qui ont été esquissées en ce sens ont tourné court. La saisie méthodique des faits extérieurs, exigée par le naturalisme et le behaviorisme, et tout au moins encouragée par le positivisme et les recherches sociales, ne peut que passer à côté des faits culturels; elle ne peut qu'avoir en horreur les idées et les significations, tout l'aspect intérieur de l'agir auquel la culture est attachée d'une manière ou d'une autre. A tout cela s'ajoute enfin le souhait de posséder, à des fins de légitimation académique, un objet qui ne se confonde avec aucun autre et qu'il ne soit pas nécessaire de partager avec d'autres disciplines. La structure a satisfait toutes ces attentes.

Les contraintes, les intérêts et les nécessités pratiques ont œuvré dans le même sens. D'autant plus tributaire de la demande qu'elle aspirait à jouer un rôle public de conseil scientifique, la sociologie a été contrainte de s'adapter aux intérêts immédiats de ses clients potentiels, qui avaient besoin, autant que possible, d'un savoir directement exploitable par l'administration. La pression des problèmes sociaux et politiques, qui étaient eux-mêmes des problèmes de structure ou qui ne permettaient, lorsqu'on tentait de les résoudre, que d'adopter des mesures structurelles, a donné à ce travail sociologique la bonne conscience d'une responsabilité sociale.

Pour ces raisons méthodologiques et pratiques, concrètes mais aussi extérieures, les faits culturels ont été écartés du champ de la conscience, tandis que le travail sociologique s'est réduit aux questions de structure. Ce refoulement a en fin de compte été conforté par l'institution lorsque la sociologie s'est professionnalisée et est devenue une discipline restreignant la formation de sa propre relève à une pure étude de la sociologie, autrement dit, précisément: des structures. Dès lors a fait défaut aux sociologues la simple connaissance des faits culturels empiriques que retiennent les sciences de l'esprit. Cette ignorance a permis de perpétuer en toute bonne conscience la restriction à la structure et a privé la notion de culture de tout fondement factuel susceptible de lui conférer une crédibilité.

Le repli sur la société a trouvé au demeurant une caution dans d'autres faits, à commencer par de puissants courants de l'époque. Les intérêts de la sociologie ont eu d'emblée partie liée avec les paradoxes de l'industrialisation et de la modernisation, qui a imposé à l'homme la société comme matrice décisive de son existence. De fait, dans la démocratie de masse, l'espace vital spirituel de la culture est devenu marginal et a été réduit à un statut en apparence accessoire et sans conséquence. Sous la pression de ces faits, et encouragée par le marxisme qui rencontrait alors un fort écho, une nouvelle conception de l'histoire a eu tendance à s'imposer au tournant du siècle; elle a trouvé son expression la plus évidente dans la polémique contre l'histoire des idées telle 
qu'elle avait été pratiquée jusque là. Ce qui aurait pu être un correctif salutaire est bien souvent devenu une pétition de principe : l'histoire était, je cite, «l'histoire des petites gens et des masses ", autrement dit : c'était là ce qu'elle devait être. C'est ainsi que la culture, qui était apparue aux générations précédentes comme une réalité tangible, a revêtu un tour irréel et suspect. De fait, cette évolution a entraîné une mise à l'écart de la culture sous la forme qui avait été la sienne au XIX ${ }^{e}$ siècle. Le mot de Goebbels est fameux: "Quand j'entends le mot culture, je sors mon revolver. » Mais il faudrait être aveugle pour ne pas voir que, pour le national-socialisme, le pouvoir culturel était aussi important que le pouvoir social et politique. Il ne pouvait en être autrement. Si la culture a disparu au sens et sous la forme qui étaient les siens au XIX ${ }^{\mathrm{e}}$ siècle, il faut en prendre acte. La question qui se pose immédiatement est de savoir en quoi a consisté ce changement de forme, et quel est le nouveau visage -et la situation- de la culture aujourd'hui. Cependant, au lieu de constater ce déplacement profond des coordonnées générales de la réalité, la sociologie n'a fait que le figer. Au lieu de prendre la mesure de son temps, elle s'est adaptée à la mesure du temps.

\section{L'essor et le déclin du concept de culture comme expression du changement culturel}

C'est au XIX ${ }^{e}$ siècle qu'a été créé le concept social de culture et que la culture est devenue une puissance à part entière, dotée d'un contenu spécifique ${ }^{9}$. Herder, aujourd'hui presque oublié en Allemagne et que l'on redécouvre à l'étranger comme un penseur révolutionnaire ${ }^{10}$, a rompu avec l'idée de progrès universaliste des Lumières en faisant une découverte riche de conséquences : les peuples sont des cultures devenues historiques qui, en raison de leur singularité, ne peuvent être confondus avec aucun autre. Les sciences de l'esprit ont approfondi cette notion de culture grâce à leur travail historique et systématique.

Cependant, la notion de culture du XIX ${ }^{e}$ siècle n'est pas seulement le résultat et l'outil de la recherche scientifique. Elle fait partie de l'histoire des dogmes, mais aussi de l'histoire de la société, parce qu'elle est devenue, on le sait, un élément central de l'idée que la société de l'époque se fait d'elle-même. La sociologie actuelle est démunie face à ce fait important -l'éducation comme instrument d'ascension, l'attention portée à la culture comme soutien du pouvoir, les idées comme fuite hors de la politique. Que la notion de culture ait été écartée, au cours de notre siècle, de l'idée que la société se fait d'elle-même, qu'elle ait été réduite à un domaine socialement accessoire, la vie culturelle, et qu'elle ait fait place à un pur concept de la société, n'a au premier abord rien de frappant et pourrait apparaître comme une normalisation à laquelle on pouvait s'attendre. Pourtant, il faut voir dans l'essor et le déclin de ce concept un processus important de l'histoire de la société, un changement dans la vision culturelle que celleci avait d'elle-même et une mutation dans la situation de la culture, qui a eu des conséquences décisives pour l'existence de la société dans son ensemble. Bien entendu, les connaissances des sciences de l'esprit ont été intégrées dans la notion de culture du $\mathrm{XIX}^{\mathrm{e}}$ siècle. Mais seule la situation singulière de la culture à cette époque a fait entrer cette notion dans la définition que la société se donnait d'elle-même et l'a enrichie de nouveaux éléments. De la même façon, le déclin du concept au cours du XX ${ }^{e}$ siècle est le résultat d'une nouvelle situation de la culture. 

allant de soi ; ce n'est qu'à partir de la distance qui les a rendus problématiques que des concepts généraux comme la religion ou le mythe sont devenus nécessaires et possibles. Il n'en va pas autrement du concept de culture, qui n'a pu être forgé que lorsqu'une distance nouvelle s'est creusée par rapport aux puissances culturelles traditionnelles et qu'il est devenu nécessaire de disposer d'un tel concept. Dans sa propre compréhension, le concept de culture désignait bien les puissances qui, avec la sécularisation, avaient été les héritières de l'autorité spirituelle de la religion.

Dans des temps de crises et de conflits, le Moyen Age trouva un soutien dans la religion qui, placée sous la protection institutionnelle de l'Eglise, donnait à l'homme une place bien définie dans l'ordre du monde et fournissait par là un repère pour l'orientation spirituelle et morale. Les bouleversements introduits par la Réforme favorisèrent l'Etat séculier, qui dut fonder, par le biais d'une argumentation non religieuse, les droits et les devoirs de l'homme à partir de sa nature et de la raison comme prérogative du genre humain, et déclarer que la religion était une affaire privée. La philosophie et la science s'affirmèrent ainsi comme des puissances absolument autonomes, qui revendiquaient une hégémonie spirituelle et morale, à côté de la foi. Elles aussi présentèrent au début leur pouvoir comme la manifestation d'une évidence, mais elles se divisèrent en différents courants d'idées. L'homme était pris entre différentes puissances culturelles, les anciennes, qui lui étaient familières, et les nouvelles, qui étaient désunies. Ce qui était nouveau, dans cette situation, c'est aussi qu'il n'y avait plus d'instance susceptible de trancher le conflit. Ce qui était nouveau également, c'est que les puissances modernes ne se limitaient plus à un message unique et définitif ; au lieu de cela, elles produisaient constamment de nouvelles idées et connaissances et évoquaient même la possibilité d'une modernisation de la religion traditionnelle. C'est cette situation radicalement nouvelle, dans laquelle le conflit et la production des puissances culturelles elles-mêmes était devenus l'instance d'ancrage spirituel, qui a promu le concept de culture comme définition pertinente. La "culture» occupa la place laissée vacante par les traditions et la religion, elle leur succéda et l'on attendit d'elle, dès lors, une orientation, qu'elle soit objective (une vision du monde) ou subjective (l'éducation). Il est donc tout à fait logique que l'on ait tenté à bien des égards de transformer les nouvelles puissances en nouvelles religions : les religions de la science, les religions de l'éducation et des humanités ou les religions politiques. La culture était devenue la nouvelle autorité spirituelle de la société, il fallait avoir de l'éducation et, de façon générale, prendre part à la culture pour trouver une assise spirituelle et une orientation pratique, comme en témoignent justement aussi les unions éducatives ouvrières ${ }^{11}$.

Il est vrai que d'autres éléments ont nourri le concept de culture. Les cultures nationales, qui se constituèrent à partir du moment où les particularités, les mœurs et les institutions traditionnelles furent supplantées par l'histoire moderne des religions, l'Etat séculier et les formes d'un savoir profane diffusées par la philosophie, la littérature et l'art (culminant souvent dans un certain "classicisme») et qui inaugurèrent à chaque fois de nouvelles traditions, furent importantes à un double titre. D'un côté, ces formes fortement individualisées, qui ne pouvaient passer inaperçues, s'intégrèrent dans le concept de culture en fournissant des preuves particulières de la puissance de la culture transmise. D'un autre côté, ces cultures nationales séculières infléchirent partout les représentations des rapports entre les 
puissances culturelles, des finalités de leur action et des objectifs de leur conflit. C'est ainsi que les peuples européens forgèrent des représentations différentes de la situation culturelle de la société sécularisée, qui se traduisirent dans les connotations spécifiques du terme ou, comme en France, dans le choix d'un autre terme (« civilisation ») pour décrire la situation de la culture ${ }^{12}$.

Quels que soient le concept ou ses connotations, l'auto-définition de la société du XIX ${ }^{e}$ siècle comme culture était objectivement tributaire d'une nouvelle situation culturelle. Les sociétés prémodernes se présentaient incontestablement à l'observateur comme des cultures, avec leur image du monde investie dans la religion ou le mythe, qui s'accomplissait dans des cultes et des rites et devenait comportement dans des us et coutumes. Des instances sociales veillent au maintien de la culture, dont le contenu est fixé. La société moderne appréhende sa condition à travers le concept de culture : celuici conserve avant tout le caractère mouvant et fluide de la culture, qui n'est plus attachée à l'autorité d'instances et de traditions figées, mais est recréée et fixée en permanence. Conformément à cette nouvelle situation, le concept s'ouvre à la prise en compte de toutes les puissances possibles. Il présente surtout un double visage de Janus, parce qu'il englobe le pouvoir des traditions, des idées et des mœurs, tout en posant dans le présent la culture comme tâche à accomplir et en la prolongeant dans l'avenir en tant que processus. Sous tous ces aspects, le concept de culture, avec ses variantes, a été la formule exacte permettant de résumer l'expérience de la société moderne. Il englobe les transformations et les déplacements de la religion, la genèse d'une nouvelle intelligentsia non religieuse qui est une nouvelle instance publique, le rang des anciens pouvoirs et les prétentions des nouveaux. La réalité sociale de cette auto-définition a manifestement trouvé son expression dans l'existence d'une nouvelle couche culturelle, dans le conflit des grands courants d'idées, dans les revendications des producteurs culturels et dans les attentes de leur clientèle - tout cela, dans le cadre de l'Etat culturel.

Si le caractère de culture de la société pré-moderne sautait aux yeux, il en va de même avec la société moderne. La sociologie peut diffuser ses certitudes quant au cours ordonné du monde, régulé par un processus de différenciation irrépressible, ou bien expliquer la genèse de la société moderne comme le résultat de transformations sociales; dès que l'on aborde les temps modernes avec réalisme et sans théories préconçues, le rôle des puissances culturelles -réformes et contre-réformes, science, Lumières et courants d'idées qui en sont issus, sans lesquels il n'existerait pas de société sécularisée- ne peut être ignoré. La société moderne ne s'est pas constituée sous l'effet de purs processus sociaux qui auraient déjà existé auparavant. Elle s'est constituée sous l'effet d'un changement radical qui n'a pas seulement transformé ses contenus, mais aussi sa structure. Ce changement a pour une part pris appui sur des transformations sociales, mais il leur a conféré pour la première fois la spécificité qui leur a permis de devenir, par delà les simples déplacements, des porteurs de la société sécularisée. Au lieu de scinder la réalité entre une histoire de l'esprit confiée à d'autres disciplines et une histoire des structures sociales, la tâche de la sociologie devrait être d'appréhender l'imbrication constante de ces courants indissociables dans l'histoire de la société réelle, qui ne peut nier son caractère culturel. Il faudra dépasser la tentative de Max Weber pour saisir en ce sens la genèse de la modernité, pas seulement parce qu'il ne l'a pas menée à son terme, mais aussi parce que la situation et la question se sont entre temps déplacées. 
38 En effet, le nouveau visage de la culture que les sociétés ouest-européennes ont composé, par le biais du processus de sécularisation issu des courants réformateurs et de la science et qui a trouvé son prolongement dans les Lumières, a manifestement disparu, sous la forme que le XIX siècle aspirait à stabiliser. Les traditions, qu'elles aient été issues de l'héritage occidental commun ou des fonds propres des cultures nationales, se sont affaiblies ou ont disparu. On a cessé de croire que, dans un processus culturel porté par le travail de l'intelligentsia de la culture, la société allait en venir, en suivant une voie prédéterminée, à résoudre ses questions et à remplir les tâches qui lui incombent ${ }^{13}$. Les ancrages sociaux autrefois associés à ce processus (la bourgeoise cultivée et l'Etat culturel) n'existent plus aujourd'hui, l'intelligentsia de la culture occupe une tout autre position dans la société et ne se conçoit plus elle-même de la même manière. La culture littéraire, artistique et intellectuelle, lorsqu'elle ne sert pas l'engagement politique, est devenue un luxe ou une industrie. La démocratie socialement constituée et politiquement organisée ne se regarde plus elle-même comme une communauté susceptible et tenue de résoudre les missions qui lui incombent en tant que culture et par la culture. Ce sont à présent des problèmes sociaux et politiques, des forces et des décisions qui passent par la constitution d'une opinion, les compromis d'intérêts et les considérations techniques, qui occupent autoritairement le devant de la scène. Ces changements patents ont contribué au refoulement des questions culturelles par les sciences sociales. La culture telle que le $\mathrm{XIX}^{\mathrm{e}}$ siècle l'entendait s'est entre-temps marginalisée ${ }^{14}$. Mais il serait absurde d'en conclure que la culture a disparu. Elle n'a plus le même visage ni les mêmes contenus, et la tâche de la sociologie est de découvrir la nouvelle forme de la culture, afin de comprendre la société actuelle dans sa dimension culturelle. La sociologie de la culture, si elle ne veut pas éluder le présent, ne peut s'orienter en fonction du concept de culture et de l'idée de la culture du XIX ${ }^{\mathrm{e}}$ siècle, ni, de façon générale, en fonction de formes antérieures, à moins de se focaliser sur des phénomènes périphériques et des problématiques erronées. La question majeure est plutôt de savoir comment la société actuelle se constitue comme culture. Si la culture sous ses formes antérieures a disparu, il faut découvrir la nouvelle forme dans laquelle elle s'est métamorphosée. La question qui se pose est donc toujours de savoir comment, où et par qui sont produites, encouragées et diffusées les idées qui sont seules à donner une orientation aux intérêts changeants et fluctuants, et à conférer un objectif et une légitimation à l'action. Le XIX ${ }^{\mathrm{e}}$ siècle fut tributaire, de ce point de vue, d'une intelligentsia culturelle circonscrite, que Theodor Geiger tenta lui aussi de définir. A l'époque des mass-média, cependant, de la société de l'éducation, des associations, du pluralisme et de la vie culturelle et éducative administrée par la politique, l'intelligentsia ne se confond plus simplement avec l'intelligentsia de la culture au sens ancien. Quelle est l'intelligentsia de cette société et comment se forme-t-elle? Quel est son ancrage social ? Dans quels courants d'idées se situe-t-elle et quels courants d'idées produit-elle ? Quelles loyautés idéelles et quelles identités sociales sont ses moteurs? Quel rôle et quelle mission revendique-telle? Quel pouvoir a-t-elle acquis par ses propres forces, quel pouvoir s'assure-t-elle en liaison avec les forces sociales et politiques? Quelles idées, quels problèmes et alternatives sont en jeu, autour de quels axes s'ordonnent-ils?

La sociologie doit faire passer ce type de questions au premier plan. Le champ des problèmes qu'elle a à traiter s'étend à l'infini, comme l'a montré la topologie ci-dessus. Si elle veut éviter l'éclatement, elle doit toujours garder en vue sa mission première, qui est de définir la société comme culture, ce qui conduit inévitablement à se 
demander où se situe l'intelligentsia, quelle est sa position sociale et en quoi consiste sa production intellectuelle. Dans les sociétés pré-modernes, ces questions ne soulèvent guère de difficultés fondamentales, mais elles deviennent délicates dès qu'on s'intéresse aux sociétés sécularisées modernes et surtout à la société actuelle. Découvrir celle-ci dans la spécificité et les problématiques du visage culturel nouveau qu'elle présente aujourd'hui, et pouvoir ainsi commencer à la comprendre adéquatement, c'est là un des grands défis auxquels est confrontée une sociologie réaliste.

\section{La signification pratique de la culture}

La question de savoir quel rôle incombe à la culture dans la société n'est pas seulement une question d'école; elle possède, au contraire, une portée essentiellement pratique. En effet, chaque société est confrontée à des difficultés qui ne peuvent être résolues que sur le plan culturel. Si la société est un fait premier, il n'en va pas autrement de la culture, dont la signification pratique est attestée par le fait qu'il n'est pas de société sans culture. Nulle part, les hommes ne se sont contentés de configurations, d'institutions et de réglementations structurelles, même si ces dernières étaient économiquement porteuses et socialement satisfaisantes. L'universalité de la religion atteste que, de toute évidence, les besoins humains dépassent l'auto-affirmation sociale. L'homme ne se présente jamais comme un pur être social. Partout, nous constatons qu'il est un être de culture, qu'il se crée un monde de significations dépassant les faits sociaux, même si elles sont mêlées à ces derniers ou conditionnées par eux. La société est viable, comme l'histoire nous l'enseigne invariablement et avec insistance, parce que, en tant que culture, elle reconnaît la limite de sa propre efficacité. Sans une culture adaptée, la société est aussi peu viable que sans une structure adaptée. Si, lorsque le contexte change, elle peut connaître le déclin à cause de problèmes structurels, elle doit aussi prendre en compte des problèmes culturels qui ne peuvent justement être surmontés qu'en faisant appel à des solutions culturelles. Son existence, au fond, n'est pas moins un problème culturel qu'un problème structurel.

41 La sociologie de la culture peut et devrait donner la preuve de son importance pratique en s'attaquant aux questions urgentes de la sociologie. Que les problèmes des pays en voie de développement soient pour une large part de nature culturelle est tout à fait évident, mais on n'en a pas encore tiré les conséquences. Il en va de même d'autres problèmes. Les immigrés et surtout les travailleurs d'origine étrangère qui s'établissent dans le pays d'accueil sont censés poser un problème d'intégration sociale, et on ne tient pas compte des graves problèmes culturels que ce processus soulève pour les deux parties. La contribution de la sociologie de la culture est encore plus urgente pour d'autres problèmes pour lesquels les explications des sciences sociales ne sont souvent que des exercices décoratifs et virtuoses, qui laissent de côté les phénomènes qu'il s'agit d'expliquer. Le terrorisme ne peut être appréhendé, et moins encore expliqué, en étudiant le milieu d'origine des criminels ou en invoquant des configurations sociales. En effet, toutes ces "causes" auraient pu entraîner mille autres réactions complètement différentes et tel a bien été le cas. Pourquoi ont-elles conduit au terrorisme, et pourquoi il existe à nouveau des terroristes aujourd'hui, c'est là la question décisive qui est ainsi éludée. Les explications données après coup pour les mouvements de contestation étudiante, pour la révolution culturelle ou les nouvelles 
sectes de jeunes passent tout autant à côté de leur objet. C'est aussi le cas lorsqu'on tente de dissimuler le problème sous des concepts insignifiants comme le «manque d'identité", voire le "défaut de sens", le fossé infranchissable qui sépare les configurations sociales censées être les causes et les phénomènes censés être les effets. Aussi longtemps qu'on reste dans le carcan de ces explications structurelles, on ne peut saisir adéquatement ni les phénomènes ni leurs causes, justement parce qu'on met tout simplement entre parenthèses les phénomènes spirituels et dotés d'un contenu, autrement dit les phénomènes culturels, et que, par suite, on se méprend sur le caractère des problèmes.

C'est en regardant à nouveau la société comme culture que la sociologie va pouvoir découvrir de nouveaux faits et des changements qui ne peuvent être retenus par ses grilles d'analyse purement structurelles. Il faudrait commencer par une approche réaliste du concept de société : la sociologie, dans ses argumentations habituelles, considère que sa réalité va de soi, alors que fait défaut la propriété essentielle d'un concept, à savoir des critères d'identification de ses objets. A l'évidence, ce concept doit beaucoup au monde pré-moderne, dans lequel les tribus, peuples et Etats étaient pour l'essentiel des unités clairement séparées, dans lesquelles l'autonomie politique et la fermeture culturelle allaient en général de pair. Ce n'est pas un hasard si Talcott Parsons est parti du principe qu'à chaque société correspondait une culture ; et ce n'est pas un hasard non plus si Georg Simmel et Max Weber ont rejeté un concept de société ainsi réifié schématiquement, parce qu'ils avaient clairement en tête les différentes dimensions de la sociétisation, et, par suite, les recoupements et les antagonismes entre les formations sociales, qui ne permettent que dans de rares cas un découpage en unités séparées ${ }^{15}$. La sociologie aurait tout intérêt à apprendre à nouveau à opérer des distinctions entre sociétisation politique et sociétisation culturelle (sans parler d'autres dimensions). A l'évidence, l'autonomie d'un Etat ne suffit pas à en faire une société, sans quoi la Slovaquie à laquelle Hitler accorda pour quelques années une existence autonome devrait être regardée comme une société. L'empire des Habsbourg était-il une société ? S'il ne parvint pas à se maintenir, ce fut en grande partie parce qu'il était composé d'une multitude de cultures nationales. Si la sociologie, d'un côté, identifie comme des sociétés des groupes tels que les Eskimos, les Navajos ou les Tziganes, en raison de leur identité culturelle, elle devrait également s'interroger sur l'identité culturelle comme dimension constitutive des sociétés lorsque, d'un autre côté, elle désigne des Etats comme des sociétés parce qu'ils sont politiquement indépendants ${ }^{16}$.

Lorsque le concept de société devient aussi vague et nébuleux, des évolutions et des faits importants demeurent ignorés. La sociologie n'a jusqu'ici guère pris en compte l'effacement des cultures nationales, qui ont porté, marqué et transformé les sociétés de l'époque moderne, sans parler d'en mesurer la signification. Mais un facteur plus lourd de conséquences encore pour l'évolution est le fait que ce déclin des cultures nationales s'accompagne d'une internationalisation de l'intelligentsia, qui trouve son expression structurelle dans la vie scientifique et les organisations internationales. Les liens de loyauté et les identités de l'intelligentsia contemporaine ne peuvent pas être situés sur la carte sociologique du monde des "sociétés ». La production d'une culture internationale unifiée, dont le succès demeure incertain, est visiblement à l'ordre du jour. Les conventions bilatérales, les organismes internationaux et les blocs politiques ne sont pas les seuls à s'ingérer au-dessus de la souveraineté des sociétés, dans le domaine des questions politiques et économiques; on voit également apparaître des groupements culturels supra-étatiques qui coiffent aussi les sociétés, qu'il s'agisse de la 
renaissance d'anciennes sphères culturelles religieuses (l'islam, par exemple), de la formation de grands courants internationaux d'idées politiques, ou d'une intelligentsia internationale de la culture. Celle-ci, avec l'internationalisation de la vie scientifique et culturelle, œuvre à la production d'une image du monde unifiée d'un point de vue intellectuel et dispose d'un grand nombre de relais pour l'imposer en pratique, parmi lesquels l'UNESCO et le PEN Club ne sont que les plus visibles. Le fait que, dans la plupart des pays, l'intelligentsia de la culture regarde aujourd'hui vers l'extérieur, que ses normes et problèmes (voire, dans une large mesure, la reconnaissance et le soutien dont elle fait l'objet) soient définis de l'extérieur et qu'elle se trouve ainsi placée à distance de sa propre société et incapable de considérer celle-ci autrement que comme le cas particulier d'un modèle universel, constitue un changement profond que l'on n'est pas en mesure de percevoir à travers le prisme d'une acception strictement structurelle de la société. Les sociétés ont perdu leur immunité culturelle et des composantes et des traditions issues des cultures les plus variées font le tour du monde et se mélangent. Une sociologie qui n'est pas en mesure de percevoir les transformations fondamentales qui viennent d'être esquissées ici et d'en mesurer la portée, ou qui, confrontée à un cas particulier sur lequel elle ne peut faire l'impasse (comme les religions de jeunes), cherche à les expliquer en invoquant des causes structurelles et en proposant d'y porter remède par des mesures structurelles, ne laisse guère escompter une évaluation réaliste de la réalité et de l'évolution sociales.

Pour finir, il faut encore évoquer au moins le service peut-être le plus important que la sociologie de la culture, si elle prend sa tâche au sérieux, peut rendre à la sociologie et peut-être à la société. La redécouverte de la société comme culture pourrait en effet nous ouvrir les yeux sur le simple fait qu'avec la sécularisation, la culture n'existe pas seulement comme tradition, mais aussi comme mission à accomplir. Elle n'est plus seulement un fait constatable, mais un problème qui confronte toute société à la question de savoir ce qu'elle veut être. Ce fait simple et fondamental a été de plus en plus occulté par l'évolution des sciences sociales. En particulier, en raison d'une interprétation malencontreuse du postulat prônant de s'affranchir des jugements de valeur, la science sociale a été confrontée à un dilemme aux graves conséquences sociales. Après avoir caressé le rêve qu'avec le progrès de la science et de la culture, les vraies valeurs se manifesteraient toujours plus clairement, elle a connu un réveil brutal et constamment tenté d'écarter les questions de valeur non seulement de la science mais aussi de la société ${ }^{17}$. Cela a été possible lorsque régnait une foi inentamée dans l'évolution sociale, comme on le voit chez Parsons, qui postulait que la société produirait indéfiniment les valeurs adaptées à elle-même et à son évolution. Lorsque la tradition culturelle de la nation était moins assurée qu'en Amérique (par exemple en Allemagne après la Première Guerre mondiale), cet axiome est devenu une construction tendant autant que possible à exclure les questions de valeurs des processus sociaux et, en tout cas, des orientations et des décisions relatives à la société. On en est alors arrivé à réduire les "questions de valeur " à des affaires privées, auxquelles les Eglises et autres groupements étaient censés apporter des réponses ou qui devaient être résolues ou réalisées dans la vie personnelle ${ }^{18}$. Cette tendance s'est accordée avec la conception purement structurelle de la société, qui n'était guère en mesure de voir dans les "valeurs" autre chose que le prolongement d'intérêts. Limitation des processus sociaux d'opinion et de décision aux organisations et aux mécanismes politiques prévus à cet effet ; compromis rationnel des intérêts avec co-participation dans l'économie, la société et la politique; limitation de ces processus aux questions touchant aux 
conditions d'existence extérieures, auxquelles on adjoint tout au plus en annexe une mystérieuse "qualité de vie»; apport, par la science sociale, des informations nécessaires aux décisions rationnelles ; tel était le concept par le biais duquel la science sociale espérait maintenir la société à l'extérieur de la zone dangereuse des « questions de valeur ", au fur et à mesure que s'est imposé un pluralisme que la science sociale avait puissamment contribué à forger en transposant à la société, sans le dire, l'axiome de la non-imposition des valeurs, qui s'appliquait à l'origine à la science, et en désignant les valeurs de la première comme un simple arbitraire subjectif ou social, parce qu'elles n'étaient pas démontrables scientifiquement.

En réalité, Max Weber - je m'en tiendrai ici à cette brève remarque- n'avait pas seulement formulé l'impératif de non-imposition des valeurs comme un impératif découlant de la logique spécifique de la science; il avait également vu en lui un rempart contre le "crépuscule des dieux des valeurs» que toute sociologie pratiquée comme une science nomothétique encourageait en présentant la réalité comme un enchaînement de faits prétendument nécessaire et une évolution ayant elle aussi force de loi, et en réduisant ainsi toutes les questions de valeur à des décisions relatives à des conditions de vie extérieures. Avec l'impératif de non-imposition des valeurs, Max Weber ne voulait pas seulement libérer la science de la corruption qui lui donnait la prétention d'énoncer des valeurs, mais aussi affranchir l'homme de la corruption de ses jugements de valeur, dont les symptômes étaient l'impossibilité, pour la science, de faire place à une autre question que celle qui concernait la situation présente des hommes, et l'incapacité à se demander ce qu'il adviendrait d'eux à l'avenir, c'est-à-dire quel type de culture ils voulaient forger ${ }^{19}$. Voilà pourquoi l'axiome de la non-imposition des valeurs ne l'entraîna pas sur la voie d'une recherche sociale empirique destinée à servir de source d'informations pour les politiques, mais plutôt sur la voie d'une sociologie de la culture cherchant à éclairer et à comprendre le caractère et la signification des alternatives à partir de la genèse historique d'une situation ${ }^{20}$. Cette option ne cachait pas un décisionnisme moral mais se fondait sur une attention portée à la dignité de l'homme, dont les prises de position sur les valeurs culturelles, moralement indépassables, constituaient justement pour lui l'expression. Il aurait tenu pour un rêve dangereux l'espoir de déduire les valeurs de discours rationnels, mais aussi la croyance qu'une société pût se perpétuer à coup de décisions politiques concernant les conditions de vie extérieures, tout en renvoyant entièrement à la sphère privée les questions de valeur et de sens, et en les écartant comme des fantaisies intellectuelles.

La société sécularisée qui n'autorise pas seulement la libre interprétation des sens ultimes, mais fait place au pluralisme en général, a elle aussi besoin, malgré tout, de valeurs officielles, qui ne peuvent être produites par un vote politique. Même une société sécularisée produit essentiellement son avenir par le biais de sa culture, autrement dit dans l'espace de significations spirituelles où des traditions sont transmises, des expériences sociales et historiques élaborées, et de nouvelles significations créées : l'éducation, la formation académique, la science, les partis, les Eglises et les mass-média sont des pouvoirs qui prennent part à ce processus; ce sont les plus visibles, mais en aucun cas les seuls. Cette évolution ne peut être appréhendée exclusivement comme un processus structurel; des phénomènes transversaux, tels les normes et valeurs fréquemment invoqués, ne peuvent être purement et simplement considérés comme un dérivé secondaire des structures. Les faits, qui ne sont jamais univoques, ne se voient conférer une signification que par le biais d'interprétations et 
de prises de position qui, lorsqu'elles ne sont pas modelées par les traditions, représentent des innovations culturelles -depuis les comportements quotidiens jusqu'aux grandes idées. Tout récemment, la révolution de la culture a bien montré que ces valeurs n'étaient pas le résultat et la conséquence aveugle de conditions sociales qui ne sont jamais univoques, mais plutôt, à bien des égards, le produit de processus culturels très variés, depuis les échanges quotidiens d'expériences sociales jusqu'aux discussions publiques sur les valeurs et à la vie scientifique, en passant par la vie éducative et culturelle. Cette société ne doit pas seulement prendre de temps en temps des décisions relatives aux conditions de vie extérieures; elle doit aussi s'accorder constamment sur le choix de la culture qu'elle veut être. Renvoyer ici au " polythéisme des valeurs » et à l'impératif scientifique de non-imposition des valeurs ne ferait que brouiller les problèmes et les faits. En effet, de même que nous sommes contraints de prendre position en tant qu'individus, indépendamment de l'impératif de nonimposition des valeurs, de la même façon, aujourd'hui, indépendamment du polythéisme logiquement indépassable des valeurs, la société produit des valeurs et des significations communes, en tout cas dominantes; celles-ci, dans une société sécularisée, n'impliquent pas une interprétation totalisante du sens du monde, mais des consensus culturels. Si nous ne pouvons pas prendre des décisions relatives aux conditions d'existence extérieures sans tenir compte des faits, sous peine d'en supporter les conséquences, nous ne sommes pas davantage en mesure de statuer sur les questions culturelles de notre existence sociale. Dès lors que la sociologie a réduit les problèmes sociaux à des questions de structure, nous avons besoin d'une sociologie de la culture qui nous permette à nouveau de comprendre à quel type de problèmes nous sommes confrontés, quels processus jouent ici un rôle décisif et quelles conditions culturelles particulières sont en jeu. Voilà pourquoi une sociologie de la culture nous est aujourd'hui nécessaire.

\section{BIBLIOGRAPHIE}

Berlin, I. (1958) : Vico and Herder, Londres.

Ferber, C. von (1959) : « Der Werturteilsstreit 1909/1959 », Kölner Zeitschrift für Soziologie und Sozialpsychologie, 11, p. 21-37.

Kroeber, A. L. (1944) : Configurations of Culture Growth, Berkeley / Los Angeles.

Kroeber, A. L. / Parsons, T. (1958) : « The Concepts of Culture and of Social System », American Sociological Review, 23, p.582-283.

Lorenz, O. (1880) : Die Geschichtswissenschaft in Hauptrichtungen und Aufgaben, Leipzig.

Parsons, T. / Bales, R.F. (1955) : Family : Socialization and Interaction Process, Glencoe (Ill.).

Simmel, G. (1993) : La Tragédie de la culture et autres essais, trad. S. Cornille et Ph. Ivernel, Paris : Rivages. 
Tenbruck, F. H. (1973) : « Die Soziologie vor der Geschichte », in : Ludz, P.C. (éd.) : Soziologie und Sozialgeschichte. Sonderheft 16 der Kölner Zeitschrift für Soziologie und Sozialpsychologie, p.29-58.

Weber, M. (1958) : Gesammelte Politische Schriften, Tübingen.

Weiß, J. (1975) : Max Webers Grundlegung der Soziologie, Munich.

Williams, R. (1958) : Culture and Society 1780-1950, Harmondsworth.

\section{NOTES}

1. Indépendamment de ce fait, le monde symbolique de la culture n'acquiert son caractère propre que lorsqu'il vise une finalité plus haute que la maîtrise immédiate du monde extérieur.

2. Il y a quelques décennies encore, les introductions à la sociologie définissaient la société comme un "héritage culturel partagé » (shared cultural heritage). Cette définition ne peut plus être retenue aujourd'hui, avec la prise en compte du concept actuel de « socialisation » (cf. infra, note 7).

3. Cf. Simmel (1993).

4. Les « représentations collectives » de Durkheim en sont un exemple.

5. Cf. Kroeber / Parsons (1958).

6. En dépit de ses connaissances historiques, le sociologue Talcott Parsons laissait la culture, réduite à des "normes et valeurs", planer comme l'esprit au-dessus de toutes les sociétés. La conception systématique de son optimisme évolutionniste exigeait l'assurance que ces valeurs se constituent d'elles-mêmes.

7. La «socialisation " était, à l'origine, l'introduction dans la culture : c'est ainsi qu'elle est encore expressément décrite par T. Parsons et R. F. Bales (1955). La psychologie sociale a privilégié la signification de « l'apprentissage social », qui a été abandonnée par la suite au profit de processus spécifiques à des rôles et à des groupes et qui, avec la renaissance du marxisme, a revêtu le caractère d'un dressage social. Sous sa forme abâtardie, le concept a été repris par les sciences de l'éducation, qui l'ont adopté sans se poser de questions lorsqu'elles se sont converties aux sciences sociales; elles en ont fait un fondement de leurs théories et réformes, sans nullement tenter de s'assurer de la signification problématique de ce concept. On pourrait parler de science de troisième main.

8. Les différents courants du positivisme ancien avaient constamment cherché à découvrir « un système naturel des périodes historiques" (Lorenz [1880]), entendu comme un système de régularités extérieures. D'autres tentatives ultérieures comme celle de Alfred Louis Kroeber (Kroeber [1944]) ont tourné court, ou ont porté préjudice aux approches rationnelles, comme dans le cas de Pitrim Alexandrovitch Sorokin. Lorsqu'elle a été en quête de régularités ou de lois extérieures, la sociologie n'a jamais pu intégrer les faits culturels et les a par suite laissés de côté. 9. Jusqu'au milieu du XVIII ${ }^{\mathrm{e}}$ siècle, dans toutes les langues, le terme était associé à un génitif qui désignait l'objet à cultiver ; il l'est encore resté par la suite en France, qui, au lieu de la culture, a fait de la civilisation le concept porteur, jusqu'à tout récemment, alors que, en Allemagne, Angleterre, Russie et d'autres pays, le concept de culture s'est imposé, dans des proportions variables. Pour l'Angleterre, nous disposons d'une étude il est vrai partiale, mais qui tente d'étudier l'emploi du terme non seulement du point de vue de l'histoire des concepts, mais aussi dans une perspective sociologique : à ce titre, elle mérite d'être lue, et aurait dû faire des émules. Il s'agit du livre de Raymond Williams (1958).

10. L'auteur n'est rien moins qu'Isaiah Berlin (1958).

11. Les associations éducatives ouvrières, qui ne se limitaient pas à dispenser des savoirs professionnels pratiques, se développèrent avant tout pour répondre à un besoin: tenir les 
ouvriers informés dans les trois grands domaines de la nouvelle culture séculière, les idées des Lumières, les richesses culturelles nationales, mais aussi la vision du monde issue des sciences de la nature. La formation des ouvriers passe en grande partie par ces processus culturels qui sont les premiers à créer, libérer ou orienter les intérêts économiques et politiques.

12. Le concept de progrès des Lumières françaises, qui trouve ses racines dans le rationalisme, et qui postulait une stricte loi d'évolution universelle fondée sur le progrès extérieur des sciences et des arts, ne laissait pas la place au concept de culture, auquel se substitua logiquement celui de civilisation, qui remplit au demeurant la même fonction dans l'auto-définition de la société sécularisée.

13. Bien que l'on raisonne encore pour une large part en termes de progrès technique, économique et social, comme si cela allait de soi, le concept de progrès est devenu problématique et la confiance dans la science et dans le progrès de la culture s'est perdue.

14. Les innovations langagières telles que "l'activité culturelle ", «la culture du loisir ", «la culture du quotidien ", etc. traduisent ce déplacement.

15. Simmel se refusa expressément à voir dans la société autre chose qu'une multiplicité de sociétisations différentes. C'était aussi le point de vue de Max Weber.

16. C'est parce qu'elle possède un fond évolutionniste que la sociologie divise la réalité sociale en " sociétés » comme unités d'enquête, tout en s'abstenant délibérément de donner des critères de définition pour ce concept. Il est grand temps de revenir aux conceptions de Simmel et Weber, qui ne considéraient pas seulement que différentes sociétisations s'imbriquaient les unes dans les autres et se superposaient au sein d'une même société, mais, plus généralement, qu'il existait des entités différentes qui se croisaient et que l'on ne pouvait faire coïncider (les sociétisations culturelles, politiques, étatiques, ethniques, etc.), dont la sociologie devait tenir compte ou qu'elle devait isoler selon la problématique étudiée. C'est ainsi, par exemple, que Max Weber, dans ses études sur l'histoire universelle, a retenu comme unités significatives les aires culturelles des religions mondiales, alors qu'elles n'ont aucune existence du point de vue de la notion habituelle de société. La notion sociologique de société représente aussi une défense face à des évolutions essentielles. Les processus, formations et sociétisations de type social, politique ou culturel qui dépassent les frontières, ne sont pas pris en compte, parce que, dans la perspective de ce concept de société, elles demeurent invisibles; même les spécificités des "sociétés " menacent constamment de disparaître derrière ce modèle de la société. A elle seule, la représentation de l'évolution sociale comme différenciation ou modernisation qui, abstraction faite de quelques processus spécifiques de transposition et d'imitation, s'opère fondamentalement dans le cadre d'une seule société, montre à quel point la sociologie est restée enfermée dans les schémas de la pensée évolutionniste du XVIII ${ }^{\mathrm{e}}$ siècle. Au fond, elle a recours, aujourd'hui comme hier, à un modèle évolutionniste limité à une société unique. Sur ce point, voir mes analyses : Tenbruck (1973).

17. On a tenté, comme je le montrerai dans une prochaine publication, de transposer à la société la prescription de non-imposition des valeurs que Weber avait formulée pour la science.

18. Cette construction part de l'hypothèse erronée que toutes les questions d'orientation et de valeur ne peuvent recevoir d'autre réponse qu'un énoncé sur le sens ultime du monde et de la vie et que, par suite, lorsque les conditions de la liberté de pensée sont remplies, elles relèvent des croyances des individus ou des communautés particulières, qui, en comblant ainsi les besoins d'orientation, affranchissent la société des encombrantes questions de sens.

19. Je m'en tiens ici à la formule que Max Weber a utilisée dans sa leçon inaugurale de Fribourg (Weber [1958], p.12). Autant que je sache, c'est la formulation la plus ancienne de ce motif durable, qui guida Max Weber dans ses questionnements.

20. A juste titre, C. von Ferber (1959), p. 30, s'était déjà inscrit en faux contre « l'idée répandue et évidente» selon laquelle l'impératif de non-imposition de valeurs au sens de Max Weber représentait l'acte de naissance de la sociologie comme science empirique du présent. Reste 
cependant à savoir comment s'opéra, chez Max Weber, la transition entre l'impératif de nonimposition des valeurs et son concept d'une histoire universelle et d'une sociologie de la culture, et, plus précisément, pourquoi il attribua à ce type de sociologie compréhensive une importance capitale pour le présent. Johannes Weiß (1975), a abordé cette question dans un contexte de monde vécu. Plus fondamentalement, le constat s'impose cependant que Max Weber, loin de tout décisionnisme, considérait que le déchiffrage de la situation culturelle par la sociologie compréhensive pouvait aider à maîtriser celle-ci d'une façon responsable et pertinente. La sociologie soumise à l'impératif de non-imposition des valeurs devait justement éclairer la situation culturelle en offrant une présentation objective de sa genèse.

INDEX

Mots-clés : sociologie de la culture

Schlüsselwörter : Kultursoziologie

\section{AUTEURS}

\section{FRIEDRICH H. TENBRUCK}

Friedrich H. Tenbruck (1914-1994), sociologue allemand, est l'un des fondateurs de la section sociologie de la culture au sein de la Société allemande de sociologie. Pour plus d'informations, voir la notice suivante. 